Arq. Bras. Med. Vet. Zootec., v.65, n.4, p.1203-1207, 2013

\title{
Qualidade da carne de bovinos superprecoces terminados em confinamento
}

\author{
[Quality of meat from super-young cattle finished in feedlot] \\ R.S. Pitombo, D.D.N. Souza, R.O.S. Ramalho, A.B.A. Figueiredo, V.C. Rodrigues, \\ D.D.G.C. Freitas, J.C.S. Ferreira \\ Instituto de Zootecnia - Universidade Federal Rural do Rio de Janeiro - Seropédica, RJ
}

\section{RESUMO}

Avaliou-se a qualidade da carne de 10 bovinos F1 Guzerá-Nelore e 10 F2 Pardo Suíço-Guzerá-Nelore, inteiros, e abatidos precocemente. Na avaliação da carne, foi utilizado o músculo Longissimus dorsi. O delineamento experimental foi o inteiramente ao acaso. Verificaram-se para F1 e F2, respectivamente, médias para umidade de 75,3 e 75,1, extrato etéreo de 1,4 e 1,5, proteína de 23,7 e 23,6 e cinzas de 1,04 e 1,06. Cor em L* de 28,9 e 30,3, médias para cor em a* de 22,6 e 23,4 e cor em b* de 15,3 15,4, força de cisalhamento de 3,4 e 3,5 , perda de peso pelo descongelamento de 9,8 e 10,5 e perda pelo cozimento de 15,9 e 15,6. Não houve diferença estatística para nenhuma das variáveis analisadas entre os grupos genéticos.

Palavras-chave: cruzamentos, extrato etéreo, gado de corte, Longissimus dorsi, qualidade da carne

\begin{abstract}
The purpose of this study was to use instrumental analysis to evaluate the chemical composition and fatty acid profile of 10 cattle Guzerath-Nellore (F1) and 10 Brown Swiss-Guzerath-Nellore (F2), intact and feedlot finished and slaughtered at 13 months. The Longissimus dorsi was used for meat evaluation. The experimental design was completely randomized. Humidity for $F 1$ and $F 2$ was respectively 75,3 and 75,1 averages, 1,4 and 1,5 averages for ether extract, proteins were 23,7 and 23,6 and 1,04 and 1,06 averages for ash. The results for $F 1$ and $F 2$, respectively, with averages for color to $L *$ of 28,9 and 30,3, averages for the color to $a^{*}$ of 22,6 and 23,4 and color to $b * 15,3$ and 15,4, averages for shear force of 3,4 and 3,4, weight loss by thawing of 9,8 and 10,5 and weight lost by cooking of 15,9 and 15,4. There were no differences in genetic groups analysis.
\end{abstract}

Keywords: beef cattle, crossbreeding, ether extract, Longissimus dorsi, meat quality

\section{INTRODUÇÃO}

Novilhos abatidos com idade média de 13 meses (superprecoce) têm a carne de melhor qualidade comparativamente com animais abatidos mais velhos, já que o aumento da idade do animal altera significativamente a maciez (Restle et al., 1999).

A avaliação da composição centesimal dos alimentos é a quantificação do lipídeo, cinzas, proteínas e umidade presentes nos alimentos, enquanto a análise instrumental fornece parâmetros de qualidade das mesmas características avaliadas pelo consumidor ao adquirir a carne, como a cor e a maciez do alimento.

A análise de umidade é caracterizada pela perda total de água e de outros componentes voláteis da amostra analisada. Os altos índices de umidade estão relacionados com a preservação e com a suculência da carne. Arboitte et al. (2004) afirmaram que carcaças com maior teor de lipídeos possuem carne de melhor palatabilidade, indicando que a gordura presente no interior das células musculares possui substâncias flavorizantes agradáveis ao paladar. A análise de

Recebido em 13 de julho de 2012

Aceito em 6 de março de 2013

E-mail: renatapitombo@hotmail.com 
minerais mostra a porção não orgânica do alimento. A carne bovina apresenta alto teor de minerais que são muito importantes à saúde humana (Lobato e Freitas, 2006).

A carne bovina é classificada como carne vermelha (Luchiari Filho, 2000). A cor da carne apresenta grande importância no momento da compra, pois é a primeira característica avaliada pelo consumidor. A perda de peso pelo descongelamento é a perda de água liberada pelas células que foram seccionadas ou se romperam pelo aumento da pressão interna durante o congelamento, e a perda na cocção é a perda de água mais uma porção menor de gordura fundida, componentes nitrogenados e minerais (Lawrie, 1981). A força de cisalhamento é uma maneira objetiva de medir a maciez utilizando-se equipamento que mede a força necessária para o corte.

Objetivou-se com este trabalho avaliar a qualidade da carne de tourinhos superprecoces $F_{1}$ Guzerá-Nelore e $\mathrm{F}_{2}$ Pardo Suíço-Guzerá-Nelore.

\section{MATERIAL E MÉTODOS}

$\mathrm{O}$ experimento foi realizado em delineamento inteiramente ao acaso. Os dados coletados foram preparados e analisados estatisticamente, conforme o pacote computacional SISVAR (Ferreira, 2000).

Foram utilizados 20 animais inteiros, que entraram no confinamento com sete meses (240kg de peso vivo) e foram abatidos aos 13 meses (450kg de peso vivo). Do total dos animais do experimento, 10 eram do cruzamento $F_{1}$ Guzerá-Nelore e 10 do cruzamento $F_{2}$ Pardo Suíço-Guzerá-Nelore.

A dieta continha aproximadamente 13,8\% de proteína bruta, para atendimento das exigências nutricionais recomendadas pelo NRC (National..., 1996), contendo $41,4 \%$ de fibra em detergente neutro (FDN), 75,98\% de nutrientes digestíveis totais (NDT), $18,15 \mathrm{Mcal}$ de energia metabolizável e 8,0kg de matéria seca.

Os animais foram abatidos após descanso, jejum e dieta hídrica de 18 horas, pelo processo tradicional, com insensibilização mecânica. Após o resfriamento da carcaça, foi retirado um bife de 2,5cm de espessura do músculo Longissimus dorsi compreendido entre a $12^{\mathrm{a}}$ e $13^{\mathrm{a}}$ costelas.

No momento das análises, uma parte de cada amostra foi descongelada a $4^{\circ} \mathrm{C}$ em geladeira por 24 horas. Foram retirados nervos, gordura separável e tecido conjuntivo, ficando apenas a carne magra. Em seguida, esta foi triturada em processador comercial. Foram feitas duas repetições na realização das análises.

O teor de umidade, proteína bruta (PB), lipídeos e minerais foi determinado pela metodologia de Silva e Queiroz (2002).

No momento da análise instrumental para classificação da cor, das perdas de peso pelo descongelamento e da cocção, uma parte de cada amostra de carne foi levada ao laboratório ainda congelada, foi pesada e, em seguida, descongelada por 24 horas até a temperatura de $4^{\circ} \mathrm{C}$. Após esse processo, foram retirados nervos, gordura separável e tecido conjuntivo, ficando apenas a carne magra.

Para análise da perda de peso pelo descongelamento, foi realizada a pesagem da amostra (uma fatia), ainda congelada, e nova pesagem foi feita depois de descongelada.

Para determinação da cor, foi empregado o sistema colorimétrico que indica diferenças de cor correspondente à sensibilidade humana. Os pedaços da amostra usados na avaliação de perdas no descongelamento foram expostos ao ar atmosférico por 30 minutos. Após isso, se fez a leitura na superfície de todos os lados de cada amostra, no total de seis leituras, e a mensuração das médias das leituras de cada amostra. O sistema de avaliação usado foi o Cielab seguindo a metodologia de Felício (1999), em que o L* mede a intensidade luminosa, $\mathrm{a}^{*} \mathrm{a}$ intensidade do verde ao vermelho e $b^{*}$ a intensidade do azul ao amarelo.

Para as perdas de peso por cocção, as amostras foram descongeladas, pesadas e colocadas para assar em grill elétrico, até alcançarem a temperatura interna de $72^{\circ} \mathrm{C}$, obtida com termômetro de ponta metálica. Em seguida, foram retiradas para sofrerem resfriamento ambiente. A perda de peso de cada amostra foi calculada pelas diferenças de peso entre as amostras antes do cozimento e após o resfriamento (Felício, 1999). 
As amostras utilizadas para determinar perda por cozimento foram aproveitadas para determinação da força de cisalhamento. Com as amostras cozidas, foram retiradas seis subamostras de $1,5 \mathrm{~mm}$ de espessura no sentido da fibra muscular e levadas ao texturômetro, onde foram obtidas as forças de cisalhamento em $\mathrm{kgf}$ (American..., 1995).

\section{RESULTADOS E DISCUSSÃO}

Os resultados das análises de umidade, extrato etéreo, proteínas e matéria mineral dos animais F1 Guzerá-Nelore e F2 Pardo Suíço-GuzeráNelore estão representados na Tab. 1. Não houve diferença $(\mathrm{P}>0,05)$ entre os grupos genéticos para nenhuma variável analisada.

A qualidade da carne é influenciada por fatores como espécie, idade, raça, alimentação e manejo. Entretanto, entre os cruzamentos estudados, essas diferenças não ficaram configuradas. Os níveis de água, proteína, lipídeos e minerais encontrados neste estudo (Tab. 1) estão de acordo com os resultados encontrados por Lawrie e Ledward (2007), em que o tecido muscular pós-rigor livre de gordura aparente apresentou $75 \%$ de água, $19 \%$ de proteína, 2,5\% de lipídeos e $1 \%$ de minerais.

Tabela 1. Médias estimadas e coeficientes de variação para as análises da composição centesimal e a avaliação instrumental da carne de animais F1 Guzerá-Nelore e F2 Pardo Suíço-Guzerá-Nelore avaliados neste experimento

\begin{tabular}{lcc}
\hline V/GG & Guzerá-Nelore & Pardo Suíço-Guzerá-Nelore \\
\hline Umidade & $75,34 \pm 0,80$ & $75,07 \pm 0,74$ \\
Extrato etéreo & $1,44 \pm 0,46$ & $1,52 \pm 0,70$ \\
Proteína & $23,73 \pm 1,05$ & $23,60 \pm 0,66$ \\
Matéria mineral & $1,04 \pm 0,05$ & $1,06 \pm 0,06$ \\
Força de cisalhamento & $3,350 \pm 0,46$ & $3,484 \pm 0,89$ \\
PP descongelamento & $9,838 \pm 2,79$ & $10,497 \pm 2,73$ \\
PP cozimento & $15,999 \pm 3.99$ & $15,353 \pm 6,29$ \\
Cor L* & $28,923 \pm 3,94$ & $30,295 \pm 4,08$ \\
Cor a* & $22,550 \pm 2,18$ & $23,422 \pm 1,97$ \\
Cor b* & $15,326 \pm 1,02$ & $15,396 \pm 1,09$ \\
\hline
\end{tabular}

V = variáveis; GG = grupos genéticos; médias com seus respectivos desvios-padrão.

Os teores de umidade estão próximos aos encontrados por Chardulo et al. (1998), que, ao trabalharem com bovinos superprecoces, encontraram valores próximos de $75 \%$ de umidade. De modo geral, o teor de proteína bruta não apresentou grande variação, os valores médios de proteína encontrados no presente estudo foram semelhantes aos encontrados por Marques (2004). O conteúdo médio de extrato etéreo encontrado neste experimento foi semelhante aos divulgados por Chardulo et al. (1998), que trabalharam com bovinos superprecoces. Kuss et al. (2006), ao trabalharem com vacas de descarte terminadas em confinamento, encontraram valores superiores aos deste experimento.

Todos os valores percentuais de cinzas ficaram próximos a 1\%. Macedo et al. (2004), ao trabalharem com tourinhos terminados em confinamento, também encontraram valores próximos a $1 \%$ para essa característica.
Os resultados das análises de cor, força de cisalhamento, perdas de peso pelo descongelamento e cocção da carne de animais F1 Guzerá-Nelore e F2 Pardo Suíço-GuzeráNelore estão representados na Tab. 1. Não houve diferença $(\mathrm{P}>0,05)$ entre os grupos genéticos para nenhuma das características avaliadas.

A cor da carne foi considerada levemente mais clara quando comparada a alguns trabalhos, como o de Abularach et al. (1998) e Silveira et al. (2006), que também investigaram essa característica, devido ao fato de os animais terem sido criados em confinamento e abatidos muito jovens.

Os valores de $\mathrm{L}^{*}$ são semelhantes aos de Costa (2009), que, ao trabalhar com 36 tourinhos Nelore, confinados, encontrou um valor médio para luminosidade de 32,85. Maiores valores de $\mathrm{L}^{*}$ indicam carne mais brilhante, portanto as amostras estudadas são mais claras que as 
obtidas por Silveira et al. (2006), que encontraram para tourinhos Nelore-Aberdeen Angus, criados a pasto, valores médios para L* de 38,77 .

Os valores de $\mathrm{a}^{*}$, entretanto, foram um pouco mais altos quanto comparados ao de Costa (2009), que encontrou média de 14,28, mas foram bem próximos ao valor encontrado por Silveira et al. (2006), que foi de 19,01. Este resultado mostra que a carne dos animais deste experimento possuiu alta intensidade de vermelho.

Por outro lado, valores de $\mathrm{b}^{*}$, no presente estudo, foram superiores aos valores médios dos dois trabalhos comparados a este, que foram de -0,06 para Costa (2009) e 4,47 para Silveira et al. (2006).

As perdas de peso devido ao descongelamento estão dentro da média quando comparadas às de outros trabalhos (Costa et al., 2002; Zakama et al., 2008); já as perdas pela cocção foram consideradas menores, o que mantém a carne mais macia e suculenta.

As perdas de peso pelo descongelamento apresentaram valores próximos aos encontrados por Arboitte et al. (2004), que, ao pesquisarem novilhos 5/8 Nelore - 3/8 Charolês, encontraram

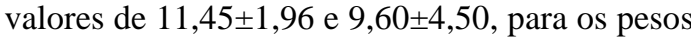
de $425 \mathrm{~kg}$ e $467 \mathrm{~kg}$, respectivamente, não havendo diferença significativa para a perda de peso pelo descongelamento entre os pesos dos animais. Os resultados para perda de peso pelo descongelamento deste estudo foram superiores aos de Vaz e Restle (2000), que encontraram para novilhos Hereford, inteiros e abatidos aos 14 meses, 3,29 $\pm 0,81$.

As perdas de peso devido à cocção foram inferiores a Arboitte et al. (2004), que

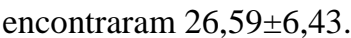

Quanto à força de cisalhamento, os resultados são semelhantes aos de Arboitte et al. (2004), que encontraram em novilhos 5/8 Nelore - 3/8 Charolês resultados iguais a $3,50 \pm 0,55 \mathrm{kgf}$ e $3,17 \pm 0,75 \mathrm{kgf}$ para os pesos de abate médios de $425 \mathrm{~kg}$ e $467 \mathrm{~kg}$, respectivamente. Esses resultados também são parecidos com os encontrados por Costa et al. (2002), que encontraram para Red Angus abatidos com $400 \mathrm{~kg}$ e $430 \mathrm{~kg}$ força de cisalhamento de 3,30 e 3,99 , respectivamente. Esses dados demonstram que animais Bos taurus e Bos indicus podem ter maciez com classificação semelhante, principalmente se abatidos precocemente.

Oliveira (2000) afirma que os zebuínos, mesmo quando abatidos mais cedo e com boa cobertura de gordura, não foram capazes de produzir carne com maciez aceitável, definida como aquela inferior a $4,5 \mathrm{kgf}$. Entretanto, a presente pesquisa demonstrou que os zebuínos abatidos precocemente e com boa camada de cobertura de gordura podem produzir carne com maciez aceitável. Não houve diferença significativa entre o Bos taurus (Pardo Suíço) com o cruzamento Bos indicus (Guzerá-Nelore) para maciez da carne. Já Restle et al. (1999) encontraram valores maiores de força de cisalhamento na carne de Bos indicus do que na carne de algumas raças Bos taurus. Esses autores concluem que a carne de Bos indicus apresenta menor maciez que a carne de Bos taurus e que, em cruzamentos, o aumento da porcentagem de genes de origem Bos indicus traz diminuição da maciez da carne.

\section{CONCLUSÃO}

O cruzamento de animais da raça Pardo Suíço com animais Guzerá-Nelore não promove mudanças na composição centesimal, na cor, na força de cisalhamento nem nas perdas de peso pelo descongelamento e cozimento da carne dos animais que receberam o mesmo tipo de dieta, quando abatidos precocemente.

\section{AGRADECIMENTOS}

A Antonio Balbino de Carvalho Neto, proprietário da Fazenda Santo Antônio, pertencente a Fazendas Reunidas Antônio Balbino Ltda.; à empresa Tortuga Cia. Zootécnica Agrária; ao professor Jorge Carlos Dias de Sousa; ao Instituto de Zootecnia da UFRRJ e à Embrapa Agroindústria de Alimentos. 


\section{REFERÊNCIAS}

ABULARACH, M.L.S.; ROCHA, C.E.; FELÍCIO, P.E. Características de qualidade do contrafilé $(\mathrm{m} . l$. dorsi) de touros jovens da raça Nelore. Cienc. Tecnol. Aliment., v.18, p.205-210, 1998.

AMERICAN meat science association-AMSA. Research guidelines for cookery, sensory evaluation and tenderness measurements of fresh meat. Natl. LiveStock and Meat Board, Chicago, IL, 1995.

ARBOITTE, M.Z.; RESTLE, J.; ALVES FILHO, D.C. et al. Composição física da carcaça, qualidade da carne e conteúdo de colesterol no músculo longissimus dorsi de novilhos 5/8 Nelore - 3/8 Charolês terminados em confinamento e abatidos em diferentes estádios de maturidade. Rev. Bras. Zootec., v.33, p.959-968, 2004.

CHARDULO, L.A.L.; SILVEIRA, A.C.; FURLAN, L.R. et al. Efeito da somatotropina bovina recombinante no desempenho e nas características químicas da carne de bovinos. Pesq. Agrop. Bras., v.33, p.205, 1998.

COSTA, E.C.; RESTLE, J.; BRONDANI, I.L. et al. Composição física da carcaça, qualidade da carne e conteúdo de colesterol no músculo longissimus dorsi de novilhos Red Angus superprecoces, terminados em confinamento e abatidos com diferentes pesos. Rev. Bras. Zootec., v.31, p.417-428, 2002.

COSTA, D.P.B. Características da carne de novilhos Nelore alimentados com caroço de algodão. Botucatu, SP: Universidade Estadual Paulista Faculdade de Medicina Veterinária e Zootecnia. 2009. 50f. Tese (Doutorado em Zootecnia) - Faculdade de Medicina Veterinária e Zootecnia, Universidade Estadual Paulista, São Paulo.

FELÍCIO, P.E. Qualidade da carne bovina: características físicas e organolépticas. In: REUNIÃO ANUAL DA SOCIEDADE BRASILEIRA DE ZOOTECNIA, 36., 1999, Porto Alegre. Anais... Porto Alegre: Sociedade Brasileira de Zootecnia, 1999. p.8997.

FERREIRA, D.F. Análises estatísticas por meio do Sisvar para Windows versão 4.0 In: REUNIÃO ANUAL DA REGIÃO BRASILEIRA DA SOCIEDADE INTERNACIONAL DE BIOMETRIA, 45., 2000, São Carlos. Anais... São Carlos: UFSCar, 2000. p.255-258.

KUSS, F.; RESTLE, J.; DESCHAMPS, F. et al. Perfil de ácidos graxos e qualidade da carne de vacas de descarte terminadas em confinamento recebendo dietas com ou sem adição de monensina. Cienc. Rural, v.36, p.1518-1523, 2006.
LAWRIE, R.A. Developments in meat science. London: Elsevier Applied Science, 1981. v.5. 342p.

LAWRIE, R.A.; LEDWARD, D.A. Lawrie's Meat Science. 7th 266 ed. Cambridge: Woodhead Pub. Ltd. . 2007. p.76.

LOBATO, J.F.P.; FREITAS, A.K. Carne Bovina: Mitos e Verdades. Pecuária Competitiva. São Paulo:FEDERACIT, 2006. 128p.

LUCHIARI FILHO, A. Pecuária da carne bovina. São Paulo: Limbife, 2000. 134p.

MACEDO, L.M.A.; ABRAHÃO, J.J.S.; PRADO, I.M. et al. Composição em umidade, cinzas, proteína e lipídeos totais do músculo longissimus dorsi de tourinhos terminados em confinamento (1). In: REUNIÃO ANUAL DA SOCIEDADE BRASILEIRA DE ZOOTECNIA, 41., 2004, Campo Grande. Anais... Campo Grande: Sociedade Brasileira de Zootecnia, 2004. (CD-ROM)

MARQUES, J.A. Indução ao anestro em novilhas bovinas e bubalinas confinadas: desempenho, comportamento e características físico-químicas da carcaça e da carne. Maringá, PR: Universidade Estadual de Maringá. 2004. 166f. Tese (Doutorado em Zootecnia) - Universidade Estadual de Maringá, Maringá

NATIONAL research council - NRC. Nutrient requirements of domestic animals. 7. ed. Washington, D.C.: National Academy Press, 1996. 242p.

OLIVEIRA, A.L. Maciez da carne bovina. Cad. Tec. Vet. Zootec., v.33, p.7-18, 2000.

RESTLE, J.; VAZ, F.N.; QUADROS, A.R.B. et al. Característica de carcaça e da carne de novilhos de diferentes genótipos de Hereford x Nelore. Rev. Bras. Zootec., v.28, p.1245-1251, 1999.

SILVA, D.J.; QUEIROZ, A.C. Análises de alimentos: métodos químicos e biológicos. 3.ed. Viçosa, MG: Editora UFV, 2002. 235p.

SILVEIRA, I.D.B.; FISCHER, V.; SOARES, G.J.D. Relação entre o genótipo e o temperamento de novilhos em pastejo e seu efeito na qualidade da carne. Rev. Bras. de Zootec., v.35, p.519-526, 2006.

VAZ, F.N.; RESTLE, J. Aspectos quantitativos da carcaça e da carne de machos Hereford, inteiros ou castrados, abatidos aos quatorze meses. Rev. Bras. Zootec., v.29, p.1894-1901, 2000.

ZAKAMA, R.; ZEOULA, L.M.; PRADO, I.N. et al. Características quantitativas e qualitativas da carcaça de novilhas alimentadas com diferentes fontes energéticas em dietas à base de cascas de algodão e de soja. Rev. Bras. Zootec., v.37, p.350-357, 2008. 